\title{
Distribution of Mangrove Species in the Islands of Jaffna Peninsula, Sri Lanka
}

\author{
Packiyanathan R. ${ }^{*}$ and Wijesundara C.S. ${ }^{2}$ \\ ${ }^{1}$ Postgraduate Institute of Science, Sri Lanka \\ ${ }^{2}$ Department of Zoology, University of Perdeniya, Sri Lanka \\ *vpraj82@gmail.com
}

\begin{abstract}
Mangroves are a group of halophytic, evergreen, woody plants and shrubs that occupy the intertidal zone. The Jaffna peninsula has some of the major mangrove sites in Sri Lanka with large extents of undisturbed mangroves. As a result of the three-decade long armed conflict that prevailed in the entire northern part of the Island, mangrove diversity and distribution has never been evaluated since 1969. The objective of the present study was to identify the mangrove species and their distribution in the Jaffna peninsula.

Five locations were selected based on the distribution of mangrove vegetation. These are Mandaitivu (East and West), Sirudivu, Kuruchidivu, Kurikadduwan, and Kaluthaipiddi. Random quadrat method was used to assess the abundance of mangrove species in the area. A total of 21 species of true mangrove plants have been recorded in Sri Lanka and the present study identified seven (07) species in the Jaffna peninsula. These are Bruguiera cylindrica, Avicennia marina, Avicennia officinalis, Rhizophora mucronata, Excoecaria agallocha, Lumnitzera racemosa, and Ceriops tagal. A mangrove associate, Acanthus ilicifolius was also recorded. Of these, Bruguiera cylindrica is a species with restricted distribution. In the present study it was recorded only from Sirudivu (density $169 / \mathrm{km}^{2}$ ). Avicennia marina is the dominant species on the Islands and Southern coastal line. The island of Mandaitivu had a high density of this species (293/ $\mathrm{km}^{2}$ on East and $1208 / \mathrm{km}^{2}$ on West Mandaitivu). Kuruchidivu also had a higher density $\left(2571 / \mathrm{km}^{2}\right)$ of this species compared to other island areas. Avicennia officinalis was restricted to Sirudivu and Kuruchidivu (density $246 / \mathrm{km}^{2}$ and $100 / \mathrm{km}^{2}$ respectively). Mangroves are one of the most diverse ecosystems and they provide suitable habitats for a large number of migratory bird species and other aquatic species such as fishes, shrimps, crabs, etc. which are important to marine fisheries in Sri Lanka. They are one of the most productive ecosystems on the earth. The mangroves also protect the coasts from the impacts of storms. The study area has large extents of relatively undisturbed mangroves, found mainly on the Eastern side of the Jaffna peninsula along with the lagoon line and the Southern part of the peninsula along the coastal line. Hence the present area has a considerable conservation value.
\end{abstract}

Keywords: True mangroves, Mangrove associates, Distribution, Islands, Jaffna Peninsula

Proceedings of the International Forestry and Environment Symposium 2016, Department of Forestry and Environmental Science, University of Sri Jayewardenepura, Sri Lanka. 